\title{
Prediction on the Energy Consumption Structure in Liaoning Province Based on System Dynamics
}

\author{
Hongyan Li', Bin Li ${ }^{2 *}$, Dongxiao $\mathrm{Niu}^{3}$ \\ ${ }^{1}$ School of Management Science and Engineering Dongbei University of Finance and Economics, China \\ ${ }^{2}$ School of Management Science and Engineering Dongbei University of Finance and Economics, China \\ ${ }^{3}$ North China Electric Power University China Energy Economic Management Research Center
}

Received: 21 January 2021

Accepted: 22 April 2021

\begin{abstract}
This paper has analyzed the influence mechanism of energy consumption structure and formed the energy consumption system from three subsystems: society and economy, energy consumption and carbon emission. Then, the paper used the theory of system dynamics to build a prediction model considering the characteristics of regional energy consumption structure. Based on the validation of the model, this paper has predicted the energy consumption structure of Liaoning province from 2019 to 2038. The results showed that under the dual effects of policy support and technological progress, the consumption proportion of coal, oil, natural gas and other fossil energy will gradually reduce, while the growth rate of carbon emissions will gradually slow down. It is suggested that the policy of "two substitutes" should be further carried out to promote the technological progress of power substitution and energy utilization.
\end{abstract}

Keywords: energy consumption structure, prediction, system dynamics, liaoning province

\section{Introduction}

First of all, on the global situation, the 2015 Paris Agreement set a global goal to limit the temperature rise to 2 degrees by 2100 , and 1.5 degrees if possible. The United Nations has also proposed the 2030 Agenda for Sustainable Development, which includes 17 sustainable development goals and 169 targets [1]. Driven by the principle of ecological civilization construction, the Chinese government has proposed medium- and longterm goals for social, economic, energy, and low-

*e-mail: libin522@163.com carbon development, especially the goal of building China into a prosperous, strong, democratic, civilized, and beautiful socialist power by 2050 , and building an energy-consuming society with an overall improvement in ecological civilization, stable total ecological energy consumption, and more than half of its energy consumption from non-fossil energy sources [2-6]. In order to achieve both domestic and global goals, accelerating the low-carbon transformation of cities is our inevitable choice, but also the choice of low-carbon urban development.

One of the key issues is how to use the transformation and upgrading of energy structure to promote the coordinated development of Chinese economy, society and environment when China's 
economy has entered a new normal, which is also an important measure to achieve sustainable development $[7,8]$. Liaoning province, as one of the key provinces in revitalizing the old industrial bases in China's Northeast area, is experiencing a critical period of comprehensive development. In the aspect of energy production and consumption, the province is facing the huge double challenges. One is the large-scale development of clean energy power generation, and the other is the new energy power accommodation. At the same time, the province needs to upgrade its energy structure. Under the dual background of energy transformation and the new normal of economy, the prediction and analysis of energy consumption structure is conducive to the layout of energy development strategy in advance, so as to improve the efficiency of long-term resource allocation [9]. In 2017, Liaoning province issued its Implementation Plan of Energy Conservation and Emission Reduction in the $13^{\text {th }}$ FiveYear Plan (2016-2020), pointing out that "by 2020, the proportion of coal in total energy consumption will drop to less than $58.6 \%$, the proportion of electric coal in coal consumption will increase to $55 \%$, the proportion of non-fossil energy in primary energy consumption will reach $6.5 \%$, and the proportion of natural gas consumption will increase to about $8 \%$ " $[10,11]$. At present, Liaoning province is being in the crucial period to achieve the dual transformation in energy structure. Therefore, it is necessary to study the evolution mechanism of energy structure combined with economic development environment, and put forward suggestions for energy transformation and development in Liaoning province, so as to provide references for the relevant policy-making.

\section{Material and Methods}

The rapid economic development is inseparable from energy, and energy plays an increasingly important role in economic development. It has also become the widespread concern about the research topics related to energy structure in the academic circles after the "oil crisis" in the 1970s, and there have been a large number of research results [12]. Based on the energy structure research in China as the main perspective, the relevant research results were summarized from four aspects: the analysis of the basic characteristics of energy structure, the influencing factors of energy structure, the prediction of energy structure and the optimization of energy structure.

The research on energy structure has been mainly focused on the national level, and in recent years, it has gradually developed into multi-dimensional research ideas, such as regional location, industry category and user type. Bilgen [13] used global energy consumption data to study the impact of $\mathrm{SO}_{x}, \mathrm{NO}_{x}$ and $\mathrm{CO}_{2}$ emissions on the environment caused by energy consumption worldwide, and elaborated that energy consumption would be an important basis for future social development, economic growth and environmental and climate change from a macro perspective. Weng [14] believed that the main reasons that have hindered the rigid change of China's energy structure were resource endowment conditions, social and economic development level, distortion in energy price system and bottleneck of renewable energy development. Qi [9] has analyzed the spatial distribution structure of carbon emission energy and industrial spatial distribution structure in Fujian province by applying the decomposition method of energy structure effect, and considered that the progress of energy utilization technology was an important means to reduce energy consumption and carbon emission, and the adjustment and optimization of energy consumption structure has great potential for emission reduction and energy conservation. Jiang et al. [2] found the basic structure of household energy consumption in Qinghai province by analyzing the household energy consumption structure in the province, and believed that there were a number of important factors affecting the energy structure, for instance, the energy price, family size, energy availability, household income and education level. Guevara et al. [15] applied the multifactor energy input-output model to spatial structural decomposition analysis, and identified the main drivers of primary energy intensity differences among fourteen European countries during the period 2000-2010. The results showed that differences in the industrial direct energy intensity and in the mix of final energy demand were the driving factors of primary energy intensity differences among countries. The above researches have focused on macro and qualitative analysis, and taken the statistical analysis of quantitative data as the argument basis. However, it needs to be pointed out that the relevant research conclusions can provide support for the prediction of energy structure, and it is also an important basis for the prediction of energy structure prediction and the establishment of the optimization model.

The research on the influencing factors of energy structure can be divided into single factor analysis and multi-factor analysis according to the different research methods and objectives. Mensah et al. [16] used econometric methods to analyze the data of fossil fuel energy consumption and economic development, and revealed that there was a two-way causal relationship between energy consumption and economic growth. Brantley [17] studied the influence of demographic factors and urbanization process on carbon emission and energy consumption, and showed that there was a complex and nonlinear relationship between population and energy consumption and carbon emission, and the degree of urbanization was positively correlated with energy consumption and carbon emission. Abreu et al. [18] identified the main determining factors for variations in energy consumption in Brazil. The results showed that there was a positive correlation between 
household income growth and energy consumption, and the distribution of energy consumption by income class accompanied the reduction of income inequality. Oluoch et al. [19] considered the ARDL panel models of 23 Sub-Saharan Africa's countries with annual data from 1998 to 2014, and found that renewable energy consumption was significant and negatively correlates with the independent variables, $\mathrm{CO}_{2}$ emissions per capita, and life expectancy index in the long run. In China, Zhou et al. [20] believed that industrial restructuring was an important driving factor in the evolution of energy consumption structure, but China has not yet formed a real energy economy. By analyzing the energy consumption structure of BeijingTianjin-Hebei and its influencing factors, Wang et al. [12] proposed that a number of factors have exerted an influence on the energy structure in different degrees, such as the regional economic growth, urbanization of permanent residents, development of the tertiary industry and energy prices. Guo [21] thought that the influencing factors of energy consumption differs in regions and levels of industrialization, and the residents' consumption level, urbanization rate, total population, energy intensity and industrial structure have different impact on the energy consumption structure. It can be concluded that different perspectives and different research methods can reach different key influencing factors of energy consumption structure. Based on the current research conclusions, the influencing factors of energy structure (Including the supply and consumption structure) can be summarized as energy restriction, carbon emission reduction policies, industrial structure, energy prices, economic growth, stages of economic development, population, etc. Foreign scholars usually use the long-range energy alternatives planning system (LEAP) to carry out the prediction research of energy consumption structure, and then analyze the impact of various policies on the supply and demand of the energy industry (2018). Perwez et al. [8] and Mirjat et al. [22] both developed Pakistan's LEAP modeling framework for structure of electric power and analyzed the impact of current energy policy on energy consumption. Among their models, Green Future (GF) and Renewable Energy Technologies (RET) were separately found to be the most sustainable electricity generation path. Similarly, Emodi et al. [23] explored Nigeria's future energy demand from 2010 to 2040 using the LEAP model, and it was found that more aggressive policy intervention by the government would lead to a decrease in energy demand in 2040. And by using LEAP model, Verdezoto et al. [24] elaborated a forecast model for the Ecuador energy sector. The model and considerations proposed would result in a final energy consumption of 158 million BOE in 2030, in which the transportation sector was the main energy consumer. Nieves et al. [25] also made a prediction about the energy demand and greenhouse gas emissions produced in Colombia through the construction of the LEAP model based on the year 2015. And apparently, in the positive scenario the economic growth of the sectors was greater and the technological substitution was accelerated which allowed a greater migration towards cleaner technologies.

The prediction research can be divided into single forecasting model and combined forecasting model based on different structures and types of the forecasting model. In the study of single forecasting model, Moonchai and Chutsagulprom [26] presented a novel approach based on a modification of multivariable grey prediction model, which was employed to estimate and predict the renewable energy consumption in Thailand along with its associated factors using the data from 1990 to 2015. Xu [27] and Li, Li and Huang [6] established the forecasting models for the total energy consumption and energy consumption structure of Chongqing city and Shandong province respectively by adopting the gray system theory. Through data analysis and verification, the model has been proved with good prediction accuracy. Xue et al. [28] made a prediction on China's total energy consumption, total coal consumption and total non-fossil energy consumption before 2020 by building the auto regressive integrated moving average model (ARIMA), and the prediction accuracy met the expectation. In the study of combination forecasting model, Liu et al. [29] proposed a combined forecast of Grey forecasting method and neural network back propagation model, and predicted coal, crude oil, natural gas, renewable and nuclear primary energy consumption volumes by Spain's 36 sub-sectors from 2010 to 2015 according to three different GDP growth scenarios. Zhang [30] built a combined forecasting model based on exponential smoothing method, ARIMA model, indirect DGM $(1,1)$ model and VAR model, and had a prediction on the energy consumption structure of China from 2016 to 2020 . Combined with the $13^{\text {th }}$ Five-Year Plan (2016-2020) of China, she carried out a scenario analysis and pointed out the policy dilemma in achieving the dual objectives of economic development and environmental protection. Zhang [31] studied the energy consumption structure based on the combination forecasting model of time series and the gray theory, and compared and analyzed the relative error and fitting model of the single forecasting model and the combination forecasting model. The research results showed that the prediction accuracy of the combined forecasting model is higher than that of the single forecasting model and the fitting effect is better.

The study of energy structure optimization refers to construct a multi-factor association model with key indicators of energy structure as the optimization objective by adopting the optimization theory of the operational research and economic theory, and its aim is to achieve the optimization and adjustment of key influencing factors of energy structure by finding the optimal solution or the sub optimal solution based on scenario analysis, which can provide support to propose relevant policies energy structure [32]. 
According to the different optimization objectives, it can be divided into single objective optimization and multi-objective optimization. Zhang [33] built an optimization model with the minimum carbon emission per unit GDP as the goal on the basis of the analysis of the development trend of energy consumption and energy structure in Beijing with the aim to optimized its energy consumption structure, and put forward policy recommendations for Beijing to achieve the goal of carbon emission reduction. Zhang and $\mathrm{Li}$ [34] built optimization models for the single goal of largest economic aggregate, the smallest total carbon emission, and the strongest fairness, as well as a multiobjective optimization model by integrating the above three objectives. They obtained the multi-objective optimization results of energy consumption structure in various industries by applying the ideal point method, and the result were used as references for making policy recommendations of China's energy development goals. Su, Chen and Yang [11] built a multi-objective optimization model from three dimensions, that is the energy consumption, energy cost and environmental impact, and proposed reasonable solutions for Beijing's energy structure optimization during the $13^{\text {th }}$ Five Year Plan period by taking Beijing as a case study.

System dynamics is the study of the dynamic complexity of systems, founded in 1956 by Professor Forrest of MIT. It is based on feedback control theory and uses computer simulation techniques to study the relationship between structure, function, and dynamic behavior of complex systems. The formation and development of system dynamics in the 1970s contributed to the worldwide emergence of sustainability theory. System dynamics emphasizes a holistic view of the system, understanding its components and the interactions of its parts, and the ability to perform dynamic simulations of the system, examining its dynamic behavior and trends when input from different parameters or different strategic factors, so that decision makers can try out different measures under different scenarios and observe the simulation results. System dynamics strives to analyze and understand the characteristics and behaviors of a system from its internal microstructure, while understanding its internal structure, parameters, and overall function. The system dynamics model is essentially a first-order differential equation with a time lag, but it is a realistic and structured modeling approach that uses computer modeling with the help of system flow diagrams, in which the flow level variables, flow rate variables, and auxiliary variables all have clear meanings. System dynamics define a complex system as a higher-order, multi-loop, and nonlinear feedback structure. A system consists of units, their motion, and information. A unit is a realistic basis for the existence of a system, while information plays a key role in the system. The units of a system depend on information to form its structure. The movement of the units is what forms the behavior and function of the system. As a relatively rigorous scientific concept, information was not recognized and utilized until the early $20^{\text {th }}$ century. Information theory provides a quantitative and mathematical description of the existence and measurement of information. Other studies have found some common patterns between the internal regulatory functions of organisms and the automatic control of machine systems, and have introduced the concept of information feedback in biological systems into machine systems, thus establishing cybernetics. Forrest examines the dynamics of socio-economic, biological and ecosystem problems, and applies the concept of information feedback to socio-economic systems first.

(1) Application of System Dynamics to Prediction Studies System dynamics methods are based on the modeling of various feedback loops formed between factors within the system, and the collection of data related to system behavior for simulation and prediction. It is superior to the regression prediction and linear planning methods in that it allows both temporal dynamic analysis and coordination between factors within the system. When predicting the water carrying capacity of a city, it is inevitable that the social, technological, ecological and earth resource domains are involved, and the cause-effect relationship is very complex. The application of system dynamics can reveal the dynamic behavior of the water resources system and provide accurate predictions.

(2) The application of system dynamics to policy management research uses system dynamics to dynamically simulate the future behavior of a system to obtain trends and directions for future system development and to propose corresponding management methods and measures to make management decisions more scientific and effective. From the existing literature, the applied research in this area is applied in enterprise management, coal safety management, and technology management.

(3) Application of System Dynamics to Optimization and Control Research Optimization and control of systems is one of the most important functions of system dynamics methods and the ultimate goal of applied system dynamics research. The factors affecting the operation and development of a system are numerous, complex, and time-varying. From a dynamic perspective, system dynamics constructs a system model, demonstrates and grasps the changes and developments of the system, and then optimizes and controls the system.

According to the decomposition principle, the system $S$ is divided into a number $(p)$ of interrelated subsystems (substructures) $S_{i}$.

$$
S=\left\{S_{i} \in S|1-p|\right\}
$$

In formula:

$S$ - represents the entire system.

$S_{i}$ - represents the subsystem.

The mathematical description is as follows: 


$$
L=P R\left[\begin{array}{l}
R \\
A
\end{array}\right]=\left[\begin{array}{l}
L \\
A
\end{array}\right]
$$

In formula:

$L-$ vector of state variables.

$R$ - rate variable vector.

$A-$ vector of auxiliary variables.

$L-$ vector of pure rate variables.

$P$ - transfer matrix.

$W$ - relationship Matrix

SD is mainly concerned with complex large systems $(S)$, which emphasizes the description of system integrity and nonlinear properties, especially the nonlinear interactions and complex feedback causeeffect relationships $(P)$ between components, substructures and sub-systems $(R)$ at different levels. In order to provide a clear description of the system, the system $S$ should be divided into a number of interrelated subsystems $P$ based on its inherent characteristics and properties, and on the basis of an as complete description of $R$ as possible, as follows.

$$
\begin{aligned}
& S=\left(P, R_{j k}\right) \\
& P=\left\{P_{i} \mid i \in I\right\} \\
& R_{j k}=\left\{r_{\mu} \mid j \in J, k \in K \& J+K=I\right\}
\end{aligned}
$$

As the world's second-largest economy, China has transformed itself into the world's largest energy producer and consumer. Its heavy reliance on fossil fuels has made China the largest emitter of greenhouse gases (GHGs) and a serious emitter of air pollution.

Low-carbon development has become a consensus in China, driven by the need to prevent climate risks, conserve resources, protect the environment, and improve low-carbon competitiveness. Over the past two decades, China's carbon dioxide emissions have increased significantly, making it the largest emitting country, and its per capita carbon emissions have exceeded the world average. In terms of resource endowment, China's development is constrained by fossil fuels. Greenhouse gas emissions and pollutant emissions have the same root, origin and synchronization, and are produced by the combustion of fossil fuels, challenging the carrying capacity of the environment, endangering public health, water, soil, and food safety.

China is at the end of industrialization and in the middle of urbanization, and energy remains the foundation for economic development. Urbanization, with its investment in infrastructure, industry, new buildings and public services, will inevitably result in increased energy consumption, and WWF believes that there is a need to think about the share of renewable energy in primary energy consumption. For example, how to develop distributed renewable energy and how to make better use of renewable energy policies and investments.
The United Nations Development Program (UNDP) is working with key stakeholders in China, including the government and the public, to address domestic environmental issues in the context of the Sustainable Development Goals. Building a low-carbon society is one of our key priorities in our work on SDG 13 "Climate Action".

In summary, a large number of research results have been formed for energy structure prediction and related research topics at home and abroad. Compared with foreign research results, China's energy structure prediction has still to be developed. At present, researches on energy structure prediction in China have mainly focused on the national energy structure, and seldom considers the differences in economic development, industrial structure and resource endowment among provinces or cities, which is hard to reflect the actual characteristics of energy structure of provinces or cities. Under the current release mechanism of energy policy in China, the prediction and analysis of provincial energy structure is more conducive to focus on the characteristics of provincial and municipal level indicators, and the analysis results can provide stronger support for provincial and local policy-making. Therefore, this paper comprehensively considered the operation mechanism and interaction relationship of economy, social and energy, and it has used the system dynamics model to build the provincial energy structure prediction model with the low-carbon and coordinated development indicators as the model parameters. Besides, the paper combined the example analysis of Liaoning province and verified the validity of the model built in this paper to provide support for policy making of the transformation of energy structure in Liaoning province.

\section{Analysis on the Influence Mechanism of Energy Consumption Structure}

\section{Analysis on the Influencing Factors of Energy Consumption Structure}

The energy structure indicator has different connotations from different perspectives. From the perspective of clean energy development, the energy structure refers to the proportion of clean energy consumption in the total energy consumption; from the perspective of primary energy, the energy structure means the proportion of coal, oil, natural gas and non-hydro renewable energy in the total energy consumption; from the perspective of final energy, the energy structure represents the proportion of electricity, gas, cold and heat in the total energy consumption. Many researchers have used the elasticity of energy production (growth rate of energy production/growth rate of the national economy) and the elasticity of energy consumption (growth rate of energy consumption/growth rate of the national economy) 
of the energy consumption relationship to reflect the level of development of the national economy and the energy production relationship, and found that both show a trend of continuous fluctuations. Because of the limitation of space and the research objectives of this paper, it mainly focused on the analysis of the energy supply structure characterized by the proportion of coal, oil, natural gas and non-hydro renewable energy consumption from the perspective of primary energy.

End-use energy is the energy directly consumed by the user, as opposed to primary energy which is the energy that is harvested directly from natural resources. End-use energy includes electricity, gasoline, and natural gas. Primary energy has energy that is usually in a form that is difficult for a consumer to extract, so energy conversion technology is used to change the form of the energy. When looking at energy use by sector, some organizations report end-use energy and some report primary energy, for a detailed discussion please see primary vs end-use accounting.

A country's complete profile of end-use energy is often called total final consumption. This is usually a compilation of how much each of the following is used:

(1) Electricity - this is neither a primary fuel nor a primary flow, but an energy currency that is produced by power plants and transported through the electrical grid.

(2) Gasoline - crude oil is a natural resource, but it must be turned into a secondary fuel like kerosene, diesel or gasoline to use as a secondary fuel in an engine.

(3) Natural gas - there is rarely a distinction made between the raw natural gas that's extracted from the ground and the consumer natural gas that's sold, although there are differences in chemical makeup.

Energy development and economic and social development are closely linked and highly coupled, which in turn determines that energy structure is closely related to economy, society, environment and resources. Based on the existing research results and multi-factor coupling relationship, there are many key factors affecting the energy structure, such as economic and social development, energy endowment, environmental constraints, technological progress and regulation policies. Among them, economic growth and population growth determine the change trend of total energy demand; the total amount and spatial distribution of energy resources determine the upper limit of energy supply capacity and its structural distribution; environmental constraints limit the scale and benchmark of energy structure; technological progress and regulation policies comprehensively reflect the impact of technology and government macroregulation on energy, economy and each link.

The main components of a system dynamics model include a causal feedback diagram, a stockflow diagram, and a functional relationship equation.
Among them, the causal feedback diagram is used to depict the causal relationships between variables, which is very effective in understanding the system structure at the beginning of modeling. The causal feedback relationships, when connected together, form a closed causal feedback loop, which is an effective tool for systems thinking because it can explain the internal causes of closed events. In system dynamics: When there is an odd number of negative feedback joints in the feedback loop, the entire feedback loop is defined as a negative feedback loop. Conversely, when there are no negative feedback joints or an even number of negative feedback joints in the feedback loop, the feedback loop is said to be a positive feedback loop. Positive feedback loops often operate in a snowball effect, an endless process of directional divergence; systems dominated by negative feedback loops converge toward a specific boundary or goal. Real socioeconomic systems have complex and self-coordinating causal feedback relationships, often consisting of several positive and negative feedback loops. The above structure is shown by the following formula.

$$
\begin{aligned}
& \operatorname{Stock}(t)=\int_{\mathrm{t}_{0}}^{\mathrm{t}}[\operatorname{Inflow}(s)- \\
& \operatorname{Outflow}(s)] d s+\operatorname{Stock}\left(\mathrm{t}_{0}\right)
\end{aligned}
$$

Stock $(\mathrm{t})$ represents the quantity of stock at time $\mathrm{t}$, Inflow(s) represents the inflow of stock, Outflows) represents the outflow of stock, Stock $\left(\mathrm{t}_{\mathrm{o}}\right)$ represents the initial quantity of stock. Flow refers to the net flow of stock in a unit time period, i.e., the rate of net change of the flow, obviously the flow can be expressed as the difference between the inflow and outflow of stock, or as a differential formula for stock:

$$
d(\text { Stock }) / d t=\operatorname{Inflow}(t)-\operatorname{Outflow}(t)
$$

\section{Structure Coupling Analysis of Energy Supply and Demand Systems}

Energy supply and demand system is a complex system highly coupled in China by many factors such as economy, population, energy consumption, energy production, policy, technology, carbon emissions and so on [1]. Due to the characteristics of regional interconnection in China's energy supply and demand system, there is no strong correlation between energy consumption and energy production in the region, and the actual statistical caliber and its statistical data are difficult to reflect the relationship between energy production and energy consumption in the region. Therefore, the impact of energy production system on energy consumption system is not considered in the construction of energy consumption structure prediction model. In this paper, the energy supply and demand system were transformed into a comprehensive system composed of economic and social subsystem, energy consumption subsystem and carbon emission 
Table 1. Components of Energy Consumption System.

\begin{tabular}{|c|c|}
\hline Subsystems & Components \\
\hline Economy and society & Population, GDP, CPI, etc. \\
\hline Energy consumption & Energy consumption of coal, oil, natural gas and water \\
\hline Carbon emission & Carbon dioxide emissions, cumulative carbon dioxide emissions, carbon emission reduction targets, etc. \\
\hline
\end{tabular}

system. The elements of each subsystem are shown in Table 1.

Each subsystem is highly coupled and interacted with each other. As an energy supply and demand system, it is also affected by technological progress, policy regulation and other factors. Each subsystem has formed a dynamic feedback structure through regulating the objectives for the energy structure and low-carbon development. The causal relationship is shown in Fig. 1.

The energy supply and demand system shown in Fig. 1 takes the energy consumption subsystem as the core, and the social and economic subsystem, carbon emission subsystem and energy consumption subsystem constitute the feedback relationship respectively. At the same time, technological progress and policy regulation factors affect the development and evolution of energy supply and demand system. Therefore, this paper has carried out quantitative analysis by introducing the technical factor, policy factor, emission factor and structural coefficients.

\section{System Dynamics Model of Energy Consumption Structure Prediction}

\section{The System Flow Diagram}

Based on the feedback structure and logical relationship of each subsystem described in Fig. 2, the regional energy structure prediction model was constructed by applying the system dynamics theory, and the system flow diagram was obtained by using Vensim PEL software.

\section{The Main Functional Relations of the Model}

(1) The social and economic system

The social and economic subsystem constructed in this paper has simplified the actual operation, only considering the impact of GDP and total population on the energy consumption structure, without considering the influence of other factors. The subsystem has contained two stocks, two flows and four instrumental variables. The two stocks were GDP and population.

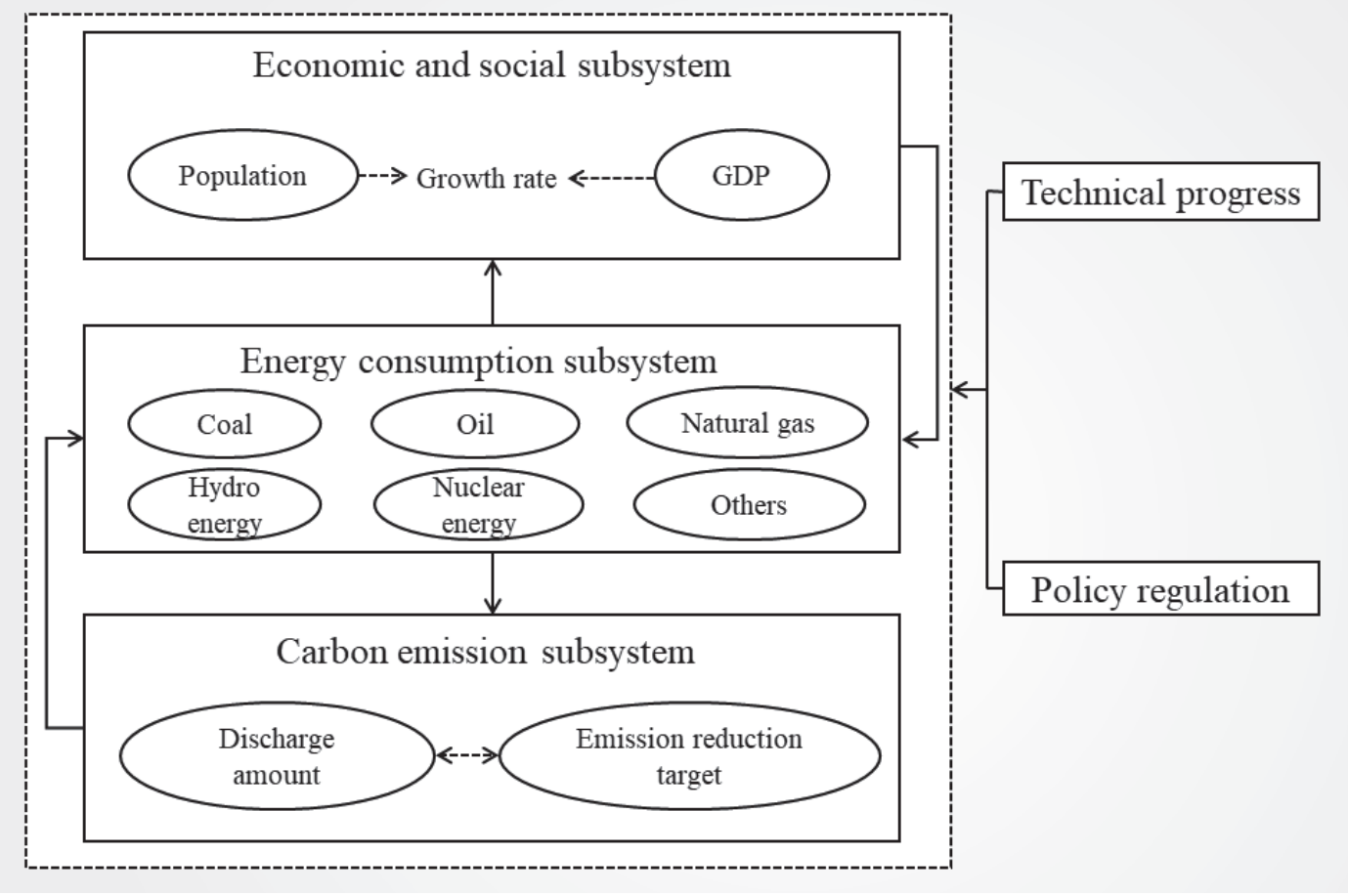

Fig. 1. Causality Diagram of Subsystems. 


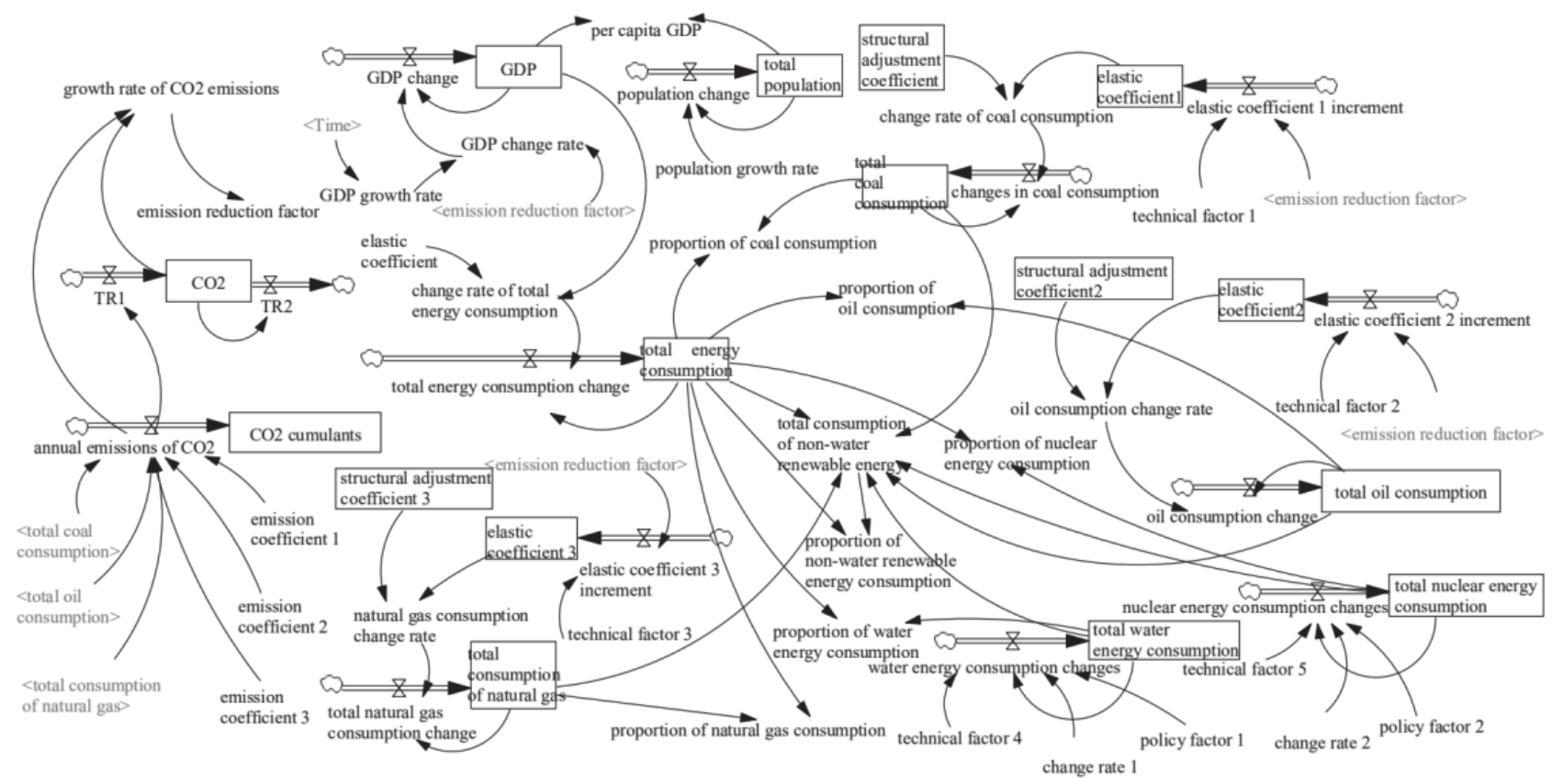

Fig. 2. System Flow Diagram of Energy Consumption Structure Prediction Model.

The functional relations of social and economic subsystem included:

Total GDP in the $\mathrm{t}$ year $=$ total GDP in the $\mathrm{t}-1$ year + variation of total GDP

Total population in the $\mathrm{t}$ year $=$ total population in the $\mathrm{t}-1$ year + variation of total population

Variation of total GDP $=$ total GDP $\times$ GDP change rate

Variation of total population $=$ total population $\times$ population change rate

\author{
GDP change rate $=$ GDP initial growth \\ rate - carbon emission factor
}

(2) Energy consumption subsystem

The energy consumption subsystem has several stocks, including overall amounts of energy demand, coal consumption, oil consumption, natural gas consumption, hydro-energy consumption and nuclear energy consumption. The subsystem was affected by the positive impact of social and economic subsystem and the negative impact of carbon emission subsystem. The functional relations of energy consumption subsystem included:

Total energy consumption in the $\mathrm{t}$ year $=$ total energy consumption in the $\mathrm{t}-1$ year + variation of total energy consumption
Variation of total energy consumption

$=$ total energy consumption $\times$ total energy consumption change rate

(3) Carbon emission subsystem

The carbon emission subsystem consisted of two stocks: annual emission of titanium dioxide and cumulative emission of carbon dioxide. At the same time, the function of emission factors, energy consumption subsystem and social economic subsystem are set up. The functional relationship of carbon emission subsystem includes:

Cumulative measurement of $\mathrm{CO}_{2}$ emission in the $\mathrm{t}$ year $=$ cumulative measurement of $\mathrm{CO}_{2}$ emission in the $\mathrm{t}-1$ year $+\mathrm{CO}_{2}$ emission in the current year

$\mathrm{CO}_{2}$ emission in current year $=$ carbon emission coefficient of coal $\times$ total coal consumption + carbon emission coefficient of oil $\times$ total oil consumption + carbon emission coefficient of natural gas + total consumption of natural gas

\section{Model Validation}

The model has selected Liaoning province in 2013 as the initial point, imputing the historical data from 2000 to 2013 to forecast the data from 2014 to 2018, and it was verified to be valid through the error analysis of the forecast data. Combined with GM $(1,1)$ model, the time series of each parameter data was calculated. Considering the economic development trend of 
Table 2. The Growth Rate of the Initial Value of Model Parameters.

\begin{tabular}{|c|c|}
\hline Simulated series & $\begin{array}{c}\text { Simulated growth } \\
\text { rate (\%) }\end{array}$ \\
\hline Total energy consumption & 3.54 \\
\hline Total coal consumption & 4.12 \\
\hline Total oil consumption & 4.67 \\
\hline Total consumption of natural gas & 10.13 \\
\hline Total hydro energy consumption & 2.87 \\
\hline Total consumption of nuclear energy & 7.67 \\
\hline
\end{tabular}

Liaoning province, the growth rate of the initial value of model parameters was presented in Table 2.

At the same time, the Implementation Plan of Energy Conservation and Emission Reduction in the $13^{\text {th }}$ Five-Year Plan (2016-2020) of Liaoning province has clearly put forward the urgency to optimize the energy structure, increase the proportion of non-fossil energy consumption, and reduce the proportion of coal consumption. Therefore, the structural adjustment coefficients of coal, oil and natural gas were set at $3 \%, 0.2 \%$ and $0.1 \%$. At the same time, considering the planning objectives of offshore wind power and nuclear power plants, the policy factors of hydro energy and nuclear energy were set at $5 \%$.

Considering that there are many design factors of system dynamics and referring to the current research results, the prediction error within $10 \%$ is an acceptable range $[35,36]$. After the above parameters were substituted into the energy consumption structure prediction model, here comes the results: the maximum error of various energy consumption was $9.23 \%$, the overall average relative error, $3.89 \%$, and the average accuracy, $96.11 \%$. Therefore, it can come to the conclusion that the prediction model has good prediction accuracy, and its prediction results are relatively reliable.

\section{Results and Discussion}

\section{Data Sources and Parameter Settings}

The data for GDP, population and $\mathrm{CO}_{2}$ emissions in the model were from Statistical Yearbook of Liaoning
Province, while the data for total consumption and production of coal, oil, natural gas, hydro energy and nuclear energy were from China Energy Statistical Yearbook.

Prediction by system dynamics required a combination of prediction scenarios, combining the scenario analysis method with system dynamics to explore the differences in the operating modes of the system under different conditions. In this paper, we focused on the analysis of the evolution of energy consumption structure in Liaoning province under the dual role of policy and technology.

Therefore, three scenarios were constructed based on the policy and technology factors:

Scenario 1 simulated the evolution of energy consumption structure stimulated by both power substitution policy and energy utilization technology, in which the policy factors for hydro and nuclear energy were set at $8 \%$, and the technology factors for coal, oil, and natural gas were set at $4 \%, 3 \%$, and $2 \%$;

Scenario 2 simulated the evolution of energy consumption structure stimulated only by the progress of energy utilization technology, in which the policy factors for hydro and nuclear energy were set at 5\%, and the technology factors for coal, oil, and natural gas were set at $3 \%, 2 \%$ and $1 \%$;

Scenario 3 simulated the evolution of the energy consumption structure stimulated only by the electricity substitution policy, in which the policy factors for hydro and nuclear energy were set at $8 \%$, and the technology factors for coal, oil, and natural gas were set at $3 \%, 2 \%$, and $1 \%$.

The final parameter settings are shown in Table 3.

\section{Projection Scenario Analysis of Energy Consumption Structure}

By replacing the values of the model parameters under the three scenarios into the energy consumption structure prediction model, the results of the energy consumption structure prediction for 2019-2038 in Liaoning province can be obtained. The results were shown in Figs 3, 4, and 5.

It can be seen that under all three scenarios, the share of coal, oil and natural gas consumption in Liaoning province showed a declining trend, among which, the share of coal consumption declined most significantly but the share of natural gas consumption more slowly.

Table 3. Parameter Setting for System Dynamics.

\begin{tabular}{|c|c|c|c|c|c|}
\hline Type & Hydro energy & Nuclear energy & Coal & Oil & Natural gas \\
\hline Scenario 1 & $8 \%$ & $8 \%$ & $4 \%$ & $3 \%$ & $2 \%$ \\
\hline Scenario 2 & $5 \%$ & $5 \%$ & $3 \%$ & $2 \%$ & $1 \%$ \\
\hline Scenario 3 & $8 \%$ & $8 \%$ & $3 \%$ & $2 \%$ & $1 \%$ \\
\hline
\end{tabular}


Overall, there is a linear trend in the change of the consumption share in the three scenarios. At the same time, it can be seen that in the energy consumption structure of Liaoning province in 2019-2038, coal and petroleum consumption share is always in an absolute position, and the sum of the two remains at the level of more than $70 \%$ of energy consumption for a long time. On top of this overall situation, alternative energy sources, such as nuclear energy and non-water renewable energy, are found to have a certain upward trend, reaching roughly $10 \%$ of the energy consumption structure in 2038, respectively.

In contrast, hydro, nuclear and non-aqueous renewables demonstrated varying degrees of growth as a result of policies and technological advances A comparative analysis revealed that: under Scenario 1, policy and technological progress provided better scope for non-aqueous renewables to grow most rapidly by reducing the fossil fuel share; under Scenarios 2 and 3, only a single factor acted on the energy consumption system, causing the fossil fuel share to decline more slowly. It indicated that in order to achieve the goal of energy transformation and upgrading, it was necessary to rely on both policy and technology, with particular emphasis on the development and utilization of non-aquatic renewable energy sources.

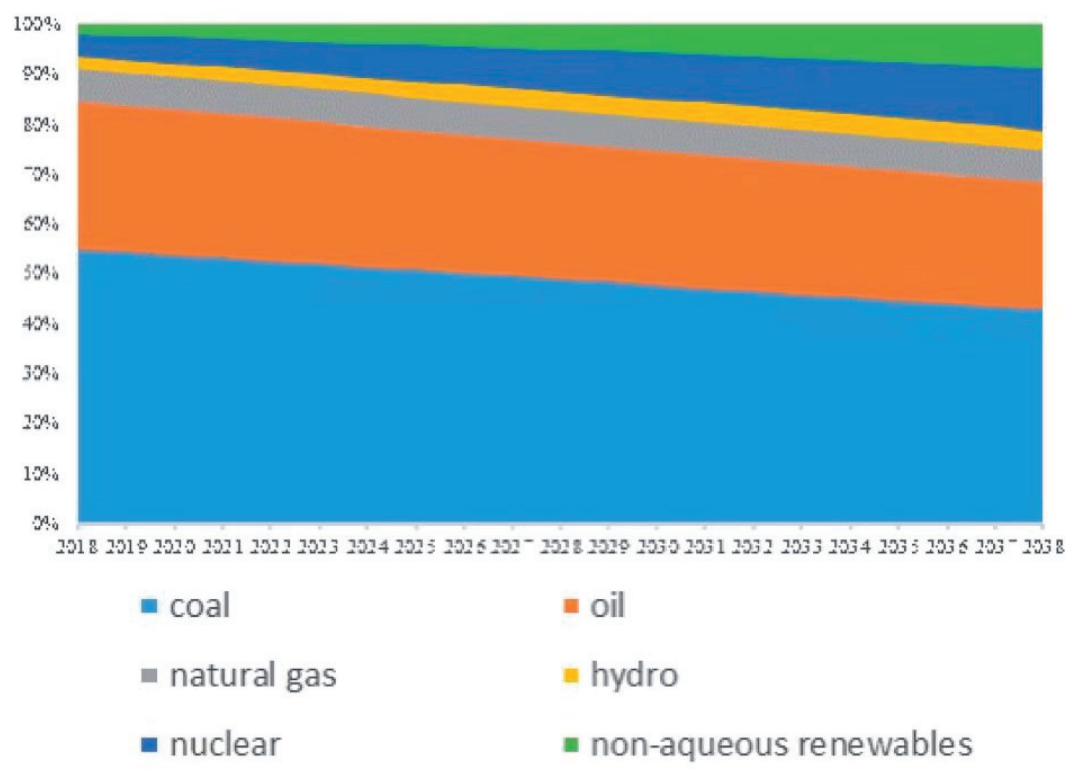

Fig. 3. Scenario 1: Structure of Energy Consumption in Liaoning Province.

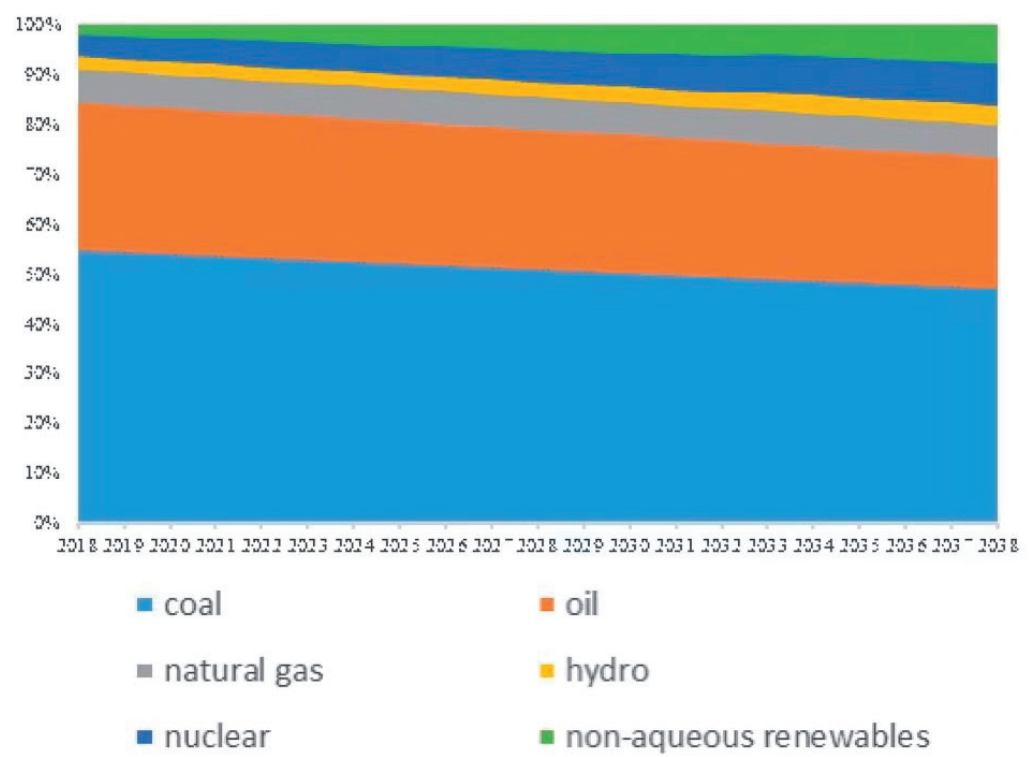

Fig. 4. Scenario 2: Structure of Energy Consumption in Liaoning Province. 


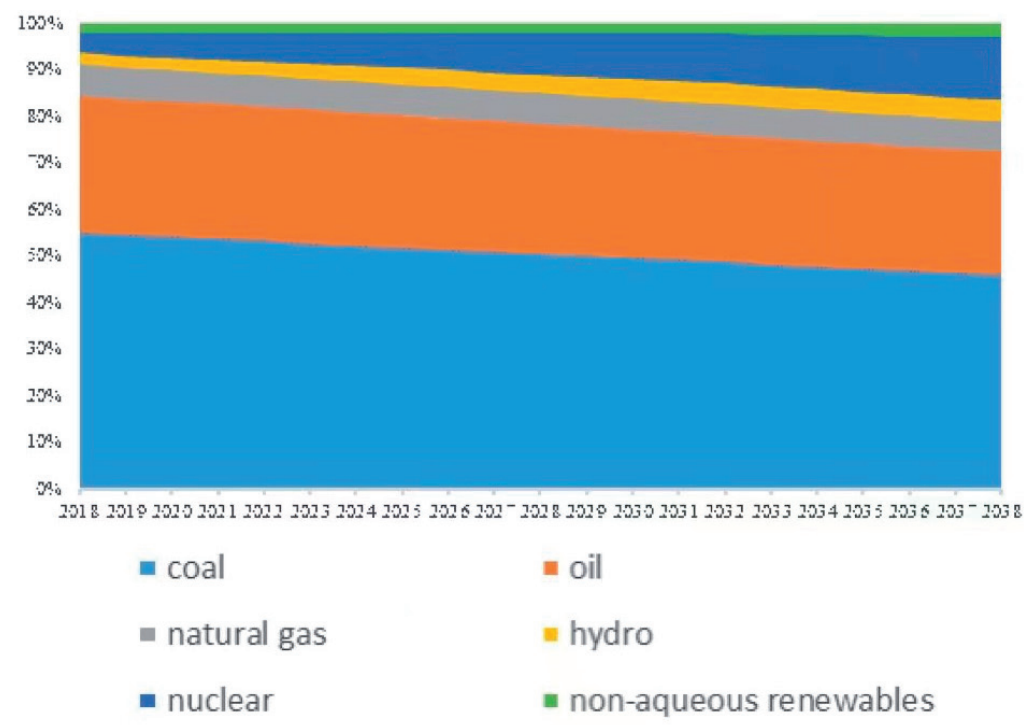

Fig. 5. Scenario 3: Structure of Energy Consumption in Liaoning Province.

\section{Suggestions on Energy Consumption Structure Transformation}

In terms of technological progress, the implementation of power substitution strategies and optimization of the overall energy layout requires the construction, development and support of the power system. According to the power substitution promotion plan designed in this research, a promotion mechanism of "government-led, grid-driven and active participation of other entities" will be constructed.

When it comes to policy formulation, the government needs to formulate electricity generation and consumption subsidies for clean energy generation. Furthermore, it's necessary to formulate a twopart tariff policy for energy storage to subsidize high-investment power substitution projects such as industrial electric furnaces, electric vehicles, thermal storage electric boilers, heat pumps, and harbor shore power to improve user acceptance.

A sound market mechanism should be established for the absorption of renewable energy to promote the construction of a regional electricity market in northeast China. It will improve the capacity of clean energy power consumption through regional integration, and optimize the participation of energy storage in the market mechanism of auxiliary services for peak adjustment in the northeast China. At the same time, the construction of markets for trading power generation rights, auxiliary services and carbon emission rights should be accelerated to give full play to the market's role in the optimal allocation of resources.

\section{Conclusions}

On the basis of analyzing the basic operation mechanism of energy consumption structure, the energy consumption system was abstracted as a complex system mutually coupled by social and economic subsystem, energy consumption subsystem and carbon emission subsystem. Then, the system dynamics theory was introduced to build a regional energy consumption structure prediction model, and the case analysis was conducted for the energy consumption structure of Liaoning province. The results showed that the model constructed in this paper was of good predictive effect. At the same time, it is feasible for Liaoning province to achieve the transformation of energy consumption structure by promoting electric energy substitution. Furthermore, it is necessary to further promote the technical progress of efficient use of energy represented by electric energy substitution.

\section{Acknowledgements}

This research was supported by the National Natural Science Foundation of China.

\section{Conflict of Interest}

The authors declare no conflict of interest.

\section{References}

1. CHAI Q., XU H. Modeling Carbon Emission Peaking Pathways in China Based on Integrated Assessment Model IAMC. China Population, Resources and Environment, 25 (6), 37, 2015.

2. JIANG L., YU L., XUE B., CHEN X. Regional Characteristics of Household Energy Consumption Structure in Qinghai Province. Economic Geography, 39 (08), 146, 2019. 
3. WANG J., MA Y., QIU Y., LIU L., DONG Z. Spatially differentiated effects of socioeconomic factors on China's NOx generation from energy consumption: implications for mitigation policy. Journal of Environmental Management, 250, 109417, 2019.

4. KULDNA P., PETERSON K., KUHI-THALFELDT R. Knowledge Brokering on Emissions Modelling in Strategic Environmental Assessment of Estonian Energy Policy with Special Reference to the LEAP Model. Environmental Impact Assessment Review, 54, 55, 2015.

5. HUANG L., LIU M. The spatial effect identification of regional carbon intensity and energy consumption intensity of China. Communications in Computer \& Information Science, 482, 372, 2015.

6. LI X., LI X., HUANG M. Prediction of Energy Consumption and Energy Consumption Structure in Shandong Province Based on Grey GM $(1,1)$ model. Environment and Sustainable Development, 37 (05), 67, 2012.

7. SHANG M., WU L. Study on the China Regional Economic Growth and Energy Consumption Intensity Difference Convergence. AIP Conference Proceedings, 1829 (1), 1, 2017

8. PERWEZ U., SOHAIL A., HASSAN S.F., ZIA U. The Long-Term Forecast of Pakistan's Electricity Supply and Demand: An Application of Long-Range Energy Alternatives Planning. Energy, 93, 2423, 2015.

9. QI S., LIU B., ZHANG Y., WANG X., WEN R. Study on Distribution Structure and Driving Factors of Carbon Emission in Fujian Province. Mathematics in Practice and Theory, 46 (07), 1, 2016.

10. SHANG M. Analysis on Regional Difference of Causal Relationship between Energy Consumption Intensity and Economic Growth in Eastern, Central and Western China. Advanced Materials Research, 3137, 1592, 2014.

11. SU M., CHEN C., YANG Z. Urban Energy Structure Optimization at the Sector Scale: Considering Environmental Impact Based on Life Cycle Assessment. Journal of Cleaner Production, 112 (02), 1464, 2016.

12. WANG F., SU Y. Energy Consumption Structure Change and Its Influencing Factors in Beijing-Tianjin-Hebei Region Area. Urban Problems, 08, 59, 2018.

13. Bilgen S. Structure and environmental impact of global energy consumption[J]. Renewable \& Sustainable Energy Reviews, 2014 (38), 890.

14. WENG F. China's Energy Structure Characteristics and Development Prospects. Economic Vision, 01, 90, 2012.

15. GUEVARA Z., HENRIQUES S., SOUSA T. Driving factors of differences in primary energy intensities of 14 European countries[J]. Energy Policy, 149, 112090, 2021.

16. MENSAH I. A., SUN M., GAO C., et al. Analysis on the nexus of economic growth, fossil fuel energy consumption, $\mathrm{CO}_{2}$ emissions and oil price in Africa based on a PMG panel ARDL approach[J]. Journal of Cleaner Production, (228), 161, 2019.

17. BRANTLEY L. Impact of population, age structure, and urbanization on carbon emissions/energy consumption: Evidence from macro-level, cross-country analyses[J]. Population and Environment, 35 (3), 286, 2014.

18. ABREU M., FERREIRA D.V., PEREIRA A.O., et al. Household energy consumption behaviors in developing countries: A structural decomposition analysis for Brazil [J]. Energy for Sustainable Development, 62, 1, 2021.

19. OLUOCH S., LAL P., SUSAETA A. Investigating factors affecting renewable energy consumption: A Panel Data
Analysis in Sub Saharan Africa[J]. Environmental Challenges, 4, 100092, 2021.

20. ZHOU Q., CHEN H. Analysis of the Interaction Between Energy Consumption and Industrial Structure in China. Statistics \& Decision, 34 (20), 99, 2018.

21. GUO X. Research on the Influencing Factors of Energy Consumption in the Process of China's Industrialization. Harbin Institute of Technology, 2018.

22. MIRJAT N.H., UQAILI M.A., HARIJAN K. Long-Term Electricity Demand Forecast and Supply Side Scenarios for Pakistan (2015-2050): A LEAP Model Application for Policy Analysis[J]. Energy, 165, 512, 2018.

23. EMODI N.V., EMODI C.C., MURTHY G.P., et al. Energy policy for low carbon development in Nigeria: A LEAP model application[J]. Renewable and Sustainable Energy Reviews, 68 (1), 247, 2017.

24. VERDEZOTO P., VIDOZA J.A., GALLO W. Analysis and projection of energy consumption in Ecuador: Energy efficiency policies in the transportation sector[J]. Energy Policy, 134, 110948, 2019.

25. NIEVES J.A., ARISTIZABAL A.J., DYNER I., et al. Energy demand and greenhouse gas emissions analysis in Colombia: A LEAP model application[J]. Energy, 169, 380, 2019.

26. MOONCHAI S., CHUTSAGULPROM N. Shortterm forecasting of renewable energy consumption: Augmentation of a modified grey model with a Kalman filter[J]. Applied Soft Computing, 87, 105994, 2019.

27. XU B. Prediction of Gross Energy Consumption for Chongqing Based on GM $(1,1)$ Model. Journal of Chongqing University of Technology (Natural Science), 28 (09), 130, 2014.

28. XUE L., HOU Y., YAN X., HE G. Chinese Energy Consumption Structure Prediction by Application of ARIMA. China Mining Magazine, 20 (04), 24, 2011.

29. Liu X., Moreno B., García A. S. A grey neural network and input-output combined forecasting model. Primary energy consumption forecasts in Spanish economic sectors. Energy, 115 (01), 1042, 2016.

30. ZHANG Q. Study on the Economic and Environmental Impact and the Optimization of China's Total Energy Consumption Control. China University of Mining and Technology (Beijing), 2018.

31. ZHANG C. Forecast of China's Energy Consumption Based on Combination Model. Hunan University, 2017.

32. ZOU X., WANG P. Study on the Mechanism of Industrial Structure Adjustment on the Optimization of Energy Consumption Structure. Soft Science, 33 (05), 11, 2019.

33. ZHANG Y. A Study on Energy Consumption Prediction and Energy Structure Optimization of Beijing Under the Constraint of Low-Carbon Economy. Beijing University of Technology, 2018.

34. ZHANG Q., LI B. Equilibrium Degree of China's Energy Supply-demand Structure and its Economic Effects. Science and Technology Management Research, 37 (15), 243, 2017.

35. ZHANG Y., ZHAO T. Research on the evolution trends and influencing factors of the regional difference in China's energy consumption. Biotechnology: An Indian Journal, 10 (12), 6032, 2014.

36. ZHAO Q., YAN Q. Statistical Property and Structural Character Evaluation of Regional Energy Consumption Associative Network in China. Statistics \& Decision, 34 (07), 96, 2018. 